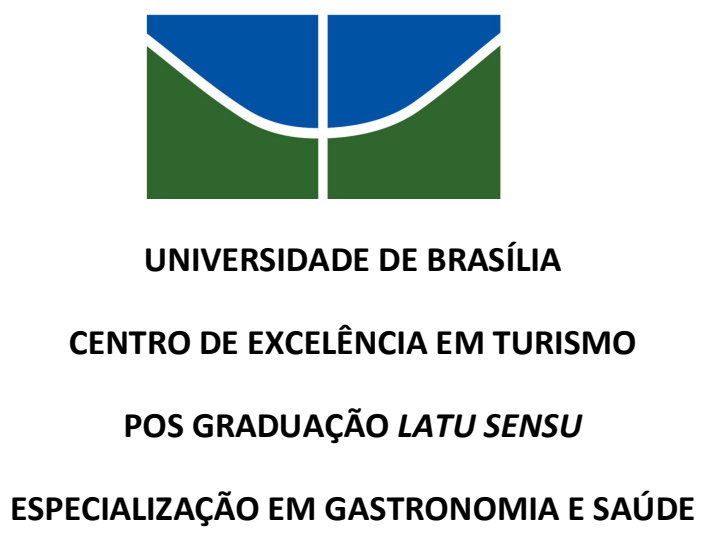

Promoção da Saúde com receitas, frutas e hortaliças do nordeste brasileiro.

Autor: José Marcos Soares Lelis

Orientador (a): Prof ${ }^{\mathrm{a}}$. Msc ${ }^{\mathrm{a}}$. Verônica Cortez Ginani

Brasília, 2008 


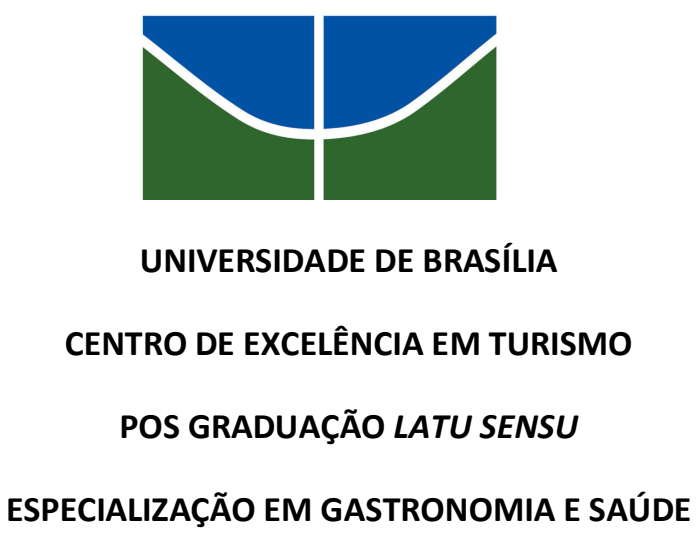

ESPECIALIZAÇÃO EM GASTRONOMIA E SAÚDE

\section{Promoção da Saúde com receitas, frutas e hortaliças do nordeste brasileiro.}

Monografia apresentada ao Curso de Pós-graduação em Gastronomia e Saúde, do Centro de Excelência em Turismo, Universidade de Brasília, como requisito parcial para obtenção do título de Especialista em Gastronomia e Saúde.

Orientador (a): Prof ${ }^{\mathrm{a}}$. Msc ${ }^{\mathrm{a}}$. Verônica Cortez Ginani

Brasília

2008 


\section{Lelis, José \\ Promoção da Saúde com receitas, frutas e hortaliças do nordeste brasileiro/ \\ José Marcos Soares Lelis \\ Monografia de especialização/ Centro de Excelência em \\ Turismo, Universidade de Brasília. Brasília, 2008. \\ Áreas de Concentração: Nutrição / Gastronomia Orientador: Prof ${ }^{a} \mathrm{Msc}^{\mathrm{a}}$ Verônica Cortez Ginani}

1. Alimentação Saudável 2. Gastronomia nordestina 3. Frutas e hortaliças5. Técnicas de produção 6. Valor imaterial. 


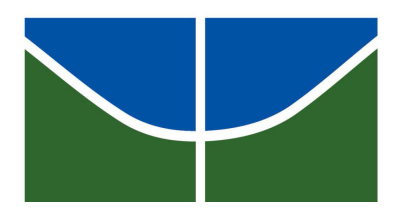

UNIVERSIDADE DE BRASÍLIA

CENTRO DE EXCELÊNCIA EM TURISMO

PÓS-GRADUAÇÃO LATO SENSU

CURSO DE ESPECIALIZAÇÃO EM GASTRONOMIA E SAÚDE

APROVADO POR:

PROFESSOR ORIENTADOR: PROF ${ }^{\mathrm{a}}$ MSC VERÔNICA CORTEZ GINANI

PROFESSOR: PROF ${ }^{\mathrm{a}}$ DR $^{\mathrm{a}}$ RAQUEL DE ASSUNÇÃO BOTELHO

PROFESSOR: PROFA MSC REANATA PUPIN ZANDONADI

BRASÍLIA, 04 DE AGOSTO DE 2008. 


\section{AGRADECIMENTOS}

A meus pais pela crença e apoio em todas as minhas decisões. À minha orientadora e amiga, Prof.(a) Verônica Cortez Ginani pela paciência, dedicação e apoio ao meu crescimento profissional e à Prof.(a) Raquel Botelho pela colaboração desde a concepção da idéia desse trabalho. 


\section{RESUMO}

Relaciona-se o consumo de alimentos com a prevalência de DCNT's (Doenças Crônicas não Transmissíveis). A ingestão elevada de gordura, assim como a de carboidratos simples e elevado teor de sódio estão, usualmente, presentes na rotina alimentar da população mundial e resultam, entre outros fatores, no acometimento da população por estas patologias. Similarmente o reduzido consumo de frutas e hortaliças, reconhecidamente fonte importante de vitaminas, minerais e fibras, está relacionado com DCNT's. Neste contexto, pesquisar e incentivar o consumo de frutas e hortaliças do nordeste brasileiro tendo como base orientações da Organização Mundial de Saúde (OMS, 2002) devem ser ações concretizadas para promoção da saúde. Este estudo, portanto, tem como objetivo desenvolver receitas regionais que utilizem como ingredientes frutas e hortaliças do nordeste brasileiro. Para seleção das receitas foram utilizados arquivos do Ministério da Saúde disponibilizados pela CGPAN (Coordenação-Geral da Política de Alimentação e Nutrição) e formulados a partir de dados enviados pelas Secretarias de Saúde Municipais do Nordeste. Para modificação das receitas, foram identificados os ingredientes com alto teor lipídico, além de elevado conteúdo de sódio adicionado e açúcares. Foram adotadas técnicas de cocção diferentes das originais para redução de tais itens, modificando o preparo. Frutas e hortaliças locais foram pesquisadas, bem como a possibilidade de integrarem as preparações escolhidas, sempre levando em consideração o valor imaterial das receitas. Foram elaborados 23 preparos, divididos entre desjejum, colação, salada, pratos principais, acompanhamentos e sobremesa, todos com composição nutricional adequada, de acordo com recomendações da OMS (2002). O consumo de preparações regionais deve ser estimulado, principalmente quando contemplam frutas e hortaliças locais, tendo em 
vista a importância nutricional deste grupo alimentar. Projetos que possuem esta finalidade devem ser prioridade nas ações pró-saúde.

Palavras-chave: Alimentação Saudável; Gastronomia Nordestina; Frutas e Hortaliças; Técnicas de produção; Valor Imaterial. 


\begin{abstract}
ASBTRACT
It relates to the consumption of foods with the prevalence of DCNT's (Chronicles not Transmitted Diseases). A high intake of fat, as well as simple carbohydrates and high in sodium are usually present in the routine of feeding the world population and result, among other factors, the involvement of the population by these diseases. Similarly the low consumption of fruits and vegetables, admittedly important source of vitamins, minerals and fibre, is related to DCNT's. In this context, to explore and encourage the consumption of fruit and vegetables from northeastern Brazil based on the Global Strategy for the Promotion of Healthy Nutrition, Physical Activity and Health, approved by the Assembly of the World Health Organization (WHO) and Food and Agriculture Organization of the United Nations (FAO) should be implemented actions to promote the consumption of such foods. This study therefore aims to develop recipes using regional ingredients such as fruit and vegetables from northeastern Brazil. The starting point was examining, from a cultural standpoint, revenue consumed by the natives of this region of the country, and propose the inclusion of fruit and vegetables typical to improve the nutritional stamp, thereby establishing the Promotion of Health. For selection of revenues were used archives of the Ministry of Health made available by CGPAN (General for Policy Coordination of Food and Nutrition) and made from data submitted by the Municipal Health Secretaries of the Northeast. To change in revenue, the ingredients were identified with high lipid content, and high content of sodium and added sugars. It was adopted different techniques of cooking for the original reduction of such items, modifying the preparation. Fruit and vegetables locations were searched, and the ability to integrate the preparations chosen, always taking into account the intangible value of revenue. 23 preparations have been
\end{abstract}


developed, divided between breakfast, lunch, salad, main dishes, funnels and dessert, all with adequate nutritional composition, according to recommendations of the WHO (2002). The consumption of regional preparations should be encouraged, especially when local fruits and vegetables contain, in view of the importance of nutritional food group. Projects that have this purpose should be the priority actions pro-health.

Keywords: Healthy Food; Northeast food; Fruit and Vegetables; techniques of production; Intangible Value. 


\section{LISTA DE FIGURAS}

Figura 1: Quantidades e distribuição das receitas nordestinas selecionadas

\section{LISTA DE QUADROS}

Quadro 1: Ingredientes e técnicas de cocção

\section{LISTA DE TABELAS}

Tabela 1: Seleção do cardápio com os tipos e as receitas

Tabela 2: Comparação dos valores lipídicos dos preparos originais e modificados

Tabela 3: Comparação da quantidade de $\mathrm{NaCl}$ adicionado aos preparos para as amostras padrão e modificadas e a quantidade na porção comparando-se com as recomendações do Ministério da Saúde

Tabela 4: Comparação da quantidade de açúcar adicionado aos preparos 


\section{INTRODUÇÃO}

A relação entre o consumo de alimentos e a prevalência de DCNT's (Doenças Crônicas não Transmissíveis) representa um dos fatores do processo de transição epidemiológica e nutricional. A ingestão elevada de gordura, assim como de carboidratos simples e elevado teor de sódio estão, usualmente, presentes na rotina alimentar da população mundial e resultam, entre outros fatores, no acometimento da população por estas patologias. Similarmente o reduzido consumo de frutas e hortaliças, reconhecidamente fonte importante de vitaminas, minerais e fibras, está relacionado com DCNT's.

Neste contexto, espera-se que medidas para promoção da saúde contemplem como uma das ações prioritárias o incentivo a alimentação saudável. Atualmente, o entendimento sobre o assunto abrange aspectos que ultrapassam questões sobre nutrientes. O gosto, cor, forma, aroma e textura são características avaliadas diretamente por quem consome o alimento, anteriormente a uma avaliação nutricional. Portanto, entender os aspectos sociais e culturais da comida é fundamental para a conceituação de alimentação saudável.

A valorização de alimentos regionais para a promoção da saúde possibilita o resgate de práticas e valores alimentares culturalmente referenciados, bem como o estímulo a produção e consumo de alimentos saudáveis regionais. Introduz no cotidiano da população frutas e hortaliças, muitas vezes presentes na vegetação local e, portanto, de fácil acesso, que foram substituídos por alimentos industrializados e com alto teor calórico. Este modelo alimentar segue uma tendência de países industrializados, onde prioriza-se a produção de alimentos em grande escala, reduzindo-se a diversidade de 
itens e padronizando-se o gosto, ou seja, induzindo a uma alimentação homogênea e desequilibrada.

Por outro lado, o consumo diário de hortaliças e frutas é considerado um fator que assegura a ingestão adequada da maioria dos micronutrientes e fibras, fato relevante para populações onde a desnutrição, com conseqüente carência de vitaminas e minerais, ainda constitui problema de Saúde Pública. Adicionalmente, o documento da Estratégia Global para a Promoção da Alimentação Saudável, Atividade Física e Saúde alerta para o fato de que o baixo consumo destes alimentos está entre os 10 fatores de risco para mortalidade e que o aumento no consumo individual desses alimentos influencia positivamente a redução da incidência de doenças como: $31 \%$ para doença isquêmica do coração; 19\% para câncer de estômago; e, 20\% para câncer esofágico.

O desequilíbrio alimentar se agrava quando se somam ao baixo consumo de frutas e hortaliças o elevado teor de sódio, gordura e açúcar, presentes em alimentos industrializados, ou em técnicas de preparo usualmente empregadas pela população. Estes elementos são importantes ingredientes culinários por conferirem às preparações, características sensoriais interessantes. Sabor, brilho, textura estão diretamente relacionados com o emprego destes itens.

Similarmente, em relação às receitas regionais, conhecidas e valorizadas por comporem os hábitos alimentares dos nativos, a quantidade de gordura utilizada pode representar um traço típico desta cozinha. São elaboradas com os ingredientes disponíveis na região e preparadas com técnicas transmitidas às gerações. Justifica-se, também neste caso, o uso da gordura dada a sua funcionalidade gastronômica, independente da etiologia da preparação.

Análise das receitas típicas nordestinas revelam o percentual do VET (Valor Energético Total) comprometido com a porção lipídica superior às recomendações da 
Organização Mundial de Saúde (OMS, 2002) na maior parte das preparações $(65,0 \%)$ (GINANI, 2004). Somam-se ao fato, estudos que indicam a necessidade de intervenções dietéticas para tornar mais saudáveis as preparações regionais servidas em restaurantes com sistema de auto-serviço. $\mathrm{O}$ fato de serem culturalmente significativas para os consumidores torna a presença no cardápio importante. Contudo, revelam-se com teor lipídico acima das recomendações para uma alimentação saudável (BOTELHO, 2006).

Para a promoção de uma alimentação saudável necessita-se, portanto, além da indicação de ingredientes adequados, que sejam repassadas para a população formas de preparar seus alimentos, que resultem em comidas saborosas e apreciadas por todos.

No nordeste brasileiro, a riqueza de frutas e hortaliças se mantém devido às características geo-climáticas da região. São inúmeras espécies, espalhados por unidades distintas: Zona da Mata, Agreste e Sertão. Essa conformação permite variações climáticas e de vegetação e interfere diretamente na produção de alimentos. Cada unidade se distingue pela propensão ao cultivo de determinados produtos, definidos também pelas necessidades de seus colonizadores (GINANI, 2004).

Explorar este potencial por meio da divulgação de receitas que utilizem frutas e hortaliças regionais, além de estarem adequadas em relação a outros aspectos nutricionais (micro e macronutrientes) pode ser uma alternativa para promoção da saúde. Com esta visão, este trabalho tem como objetivo desenvolver receitas regionais que utilizem como ingredientes frutas e hortaliças do nordeste brasileiro. 


\section{REFERENCIAL TEÓRICO}

\subsection{A ALIMENTAÇÃO}

"Há assuntos que o pensamento erudito considera como menores"

(Poulain, 2004).

Falar em alimentação, já no final do século XIX, não era algo bem visto no meio literário. Poulain mostra em "Sociologias da Alimentação" o que autores da época como Revel, Montaigne \& Rebelais e Barthes acreditavam sobre o tema. Referiam-se a "um tal assunto" como não sendo um tema sério e um tanto fútil à primeira vista. A exemplo dos livros de receitas, corriam o risco de serem criticados negativamente por escreverem tratados culinários mesmo que relevantes (POULAIN, 2004).

Contudo, atualmente, pesquisas consagradas, revelam que a alimentação não é só uma necessidade humana. Está num posto de extrema relevância logo após a respiração e à ingestão de água (CARNEIRO, 2003).

Carneiro (2003) afirma que o ato de se alimentar envolve uma série de fatores tanto materiais como imateriais. É sublimado, por muitos antropólogos, como fato sobrecarregado de idéias, ficando atrás do sexo, em relação à importância para o ser humano. Discute ainda a história da alimentação abrangendo aspectos de produção, distribuição, preparo e consumo. Diz: "O que se come é tão importante quanto, quando se come, onde se come, como se come e com quem se come.” A alimentação e suas etapas como escolhas, produção e ingestão de alimentos exercem influência decisiva na vida do homem, relacionando-se com o desempenho das ações cotidianas e até com a conservação da espécie humana (GINANI, 2004). 
A alimentação é fator primordial na rotina diária da humanidade, não apenas por ser necessidade básica, mas principalmente porque a sua obtenção tornou-se um problema de saúde pública, uma vez que o excesso ou falta podem causar doenças. Por meio da evolução histórica da alimentação mundial verifica-se que a gastronomia, recursos, hábitos e padrões alimentares, são aspectos importantes que auxiliam a refletir sobre a complexidade e a magnificência que permeiam as relações entre os diversos países (ABREU et al, 2001).

\subsection{HISTÓRIA DA ALIMENTAÇÃO NO BRASIL}

O padre jesuíta Cristóvão de Gouvêa relata em sua primeira carta informativa à Coroa portuguesa, em sua viagem apostólica, de maio de 1583: “A terra tem muitas frutas, ananazes, pacobas, e todo ano há frutas nos refeitórios... Legumes não faltam da terra e de Portugal; berinjelas, alfaces, couves, abóboras... e outros legumes e hortaliça" (CASCUDO, 2004)

A formação gastronômica brasileira com sua miscigenação de influências composta por europeus, africanos e os indígenas que habitavam o país, foi de extrema importância para o aproveitamento das frutas e hortaliças que eram cultivadas. Os índios dominavam formas de aproveitamento de algumas frutas e as consumiam em grandes quantidades. Com a chegada européia e seus costumes, alguns hábitos indígenas foram abandonados, e houve a incorporação das técnicas portuguesas tanto de cocção como de conservação, iniciando-se assim, a cozinha brasileira (ROMIO, 2000).

No Nordeste essa mudança foi mais enfática. Como porto para os navios portugueses, essa região do Brasil foi a primeira porta de entrada que os colonizadores encontraram. A tentativa frustrante de explorar a mão de obra indígena na produção de 
cana-de-açúcar para prover a Coroa portuguesa com algum retorno financeiro, fez com que fossem trazidos escravos das ilhas de Açores e Madeira, também território português, para a realização do plantio. Com isso não vieram somente negros para o trabalho e sim toda uma cultura africana rica em suas crendices e seus costumes e receitas que fizeram, após o declínio da lavoura da cana-de-açúcar, com que as escravas-cozinheiras tivessem acesso a uma vida mais cômoda nas cozinhas dos senhores de engenho (SENAC, 2000 e ROMIO, 2000).

Posteriormente, com a independência do país, novos povos como europeus com influências árabes se dirigiram para as diferentes regiões brasileiras. Trouxeram hábitos e ingredientes que se adaptaram às condições locais. Contribuíram, dessa forma, para diferenciar a culinária de cada região brasileira e um grande exemplo é o estado do Maranhão com seus pratos à base de gergelim como o cuxá e suas variações (SENAC, 2000).

Os hábitos alimentares no Brasil são, portanto, inicialmente, o resultado da interação das práticas alimentares dos nativos, do branco europeu e do africano, somada as diferentes condições geográficas encontradas devido à vastidão territorial do país. Contudo, há fatores de integração perceptíveis, formadores da cozinha nacional, como por exemplo, a mandioca (GINANI, 2004).

\subsection{O CONSUMO DE FRUTAS E HORTALIÇAS NO BRASIL, A QUALIDADE DE VIDA E A PROMOÇÃO DA SAÚDE}

Estima-se que o consumo de frutas e hortaliças no Brasil corresponda a menos da metade das recomendações nutricionais, sendo ainda mais deficiente entre as famílias de baixa renda. Alguns fatores sociais prejudicam o tal consumo como: preços elevados 
(diante dos demais alimentos e em comparação com a renda das famílias); sistemas ineficientes de produção, distribuição e comercialização; e, desconhecimento da população sobre a importância daqueles alimentos para a saúde, sobretudo com relação a hortaliças (JAIME, 2007).

De acordo com a OMS (2002), o baixo consumo de hortofrutícolas (frutas e hortaliças) está entre os 10 principais fatores de risco para a morbimortalidade no mundo. Tal fato é responsável por 19\% dos cancros gastrointestinais, 31\% das doenças cardiovasculares isquêmicas e $11 \%$ dos enfartes do miocárdio. Acredita-se que, potencialmente, mais de 2,7 milhões de vidas poderiam ter sido salvas se fizessem uso, nas porções adequadas, de frutas e hortaliças.

Um relatório sobre alimentação, nutrição e prevenção de DCNT publicado pela World Health Organization/Food and Agricultural Organization of the United Nations (WHO/FAO, 2002), define, para a população, metas de ingestão de nutrientes. Recomenda o consumo de, pelo menos, $400 \mathrm{~g}$ de frutas e hortaliças diariamente para a prevenção de DCNT, como doenças cardiovasculares, câncer, diabetes e obesidade. O relatório afirma que há evidências convincentes de que este grupo alimentar diminui o risco de obesidade e doenças cardiovasculares, assim como, provavelmente, o risco de diabetes (GOMES, 2007).

Segundo a VIGITEL (Vigilância de Fatores de Risco e Proteção para Doenças Crônicas por Inquérito Telefônico, 2006), um conjunto de alguns fatores de risco corresponde pela grande maioria das mortes por DCNT's e por fração substancial da carga de doenças associadas a essas enfermidades. Dentre esses fatores, destacam-se o tabagismo, o consumo excessivo de bebidas alcoólicas, a obesidade, as dislipidemias (determinadas principalmente pelo consumo excessivo de gorduras saturadas de origem 
animal), a hipertensão arterial, a ingestão insuficiente de frutas e hortaliças e a inatividade física (BRASIL, 2007).

No entanto, de acordo com a POF (Programa de Orçamento Familiar, 2003), em um consumo calórico médio de 1800 calorias, a participação das frutas e hortaliças é de 3,37\%. Correspondendo a 60 calorias e 132 gramas. Esses números divergem da recomendação da OMS (2002) que estipula o consumo em 400 gramas desse grupo alimentar diariamente no combate às DCNT's, em uma dieta de 2000 calorias.

Deve-se considerar também que as desigualdades econômicas e o acesso diferenciado aos bens e serviços públicos são fatores determinantes da situação de insegurança alimentar vivenciada pela população mais carente. $\mathrm{O}$ acesso a alimentos de boa qualidade é dificultado, assim como, aos equipamentos necessários para conserválos e prepará-los. Soma-se o desconhecimento sobre uma alimentação sadia e nutricionalmente adequada (BARROS et al, 2007).

Por outro lado, a redução da quantidade de gordura, a ponderação no uso do sal e do açúcar, uma vez que a industrialização dos alimentos e a mudança dos hábitos alimentares promovem o consumo elevado desses compostos, associado à prática de atividade física diária, tendem a favorecer e aumentar a qualidade de vida da população (GARCIA, 1997).

Para modificar este cenário, devem-se adotar medidas que promovam a melhoria do conhecimento, por meio do acesso a informações. Neste sentido, constituem base para as políticas públicas no Brasil, iniciativas como os Guias Alimentares e as Políticas de Promoção da Saúde através do consumo de frutas e hortaliças locais. Objetiva-se 
com estas medidas, favorecer a formação da consciência populacional e promover o consumo de tais alimentos como prevenção das DCNT's (NEUMANN, 2006).

Através da "Iniciativa nacional de incentivo ao consumo de frutas e hortaliças" (BRASIL, 2005), o governo brasileiro desenvolve $\mathrm{o}$ fomento ao consumo e desenvolvimento sustentável e geração de renda para pequenos produtores e agricultores familiares. Assim, a promoção de uma Alimentação Saudável se alia a outros programas como o Guia de Alimentos Regionais de 2004, elaborado pelo Ministério da Saúde, para combater a desnutrição e a obesidade.

É com base nesses dados que esta pesquisa tem como objeto de estudo receitas tradicionais do nordeste brasileiro. O objetivo é promover uma alimentação saudável, incentivando tanto o consumo de frutas e hortaliças, como diminuindo o alto teor de sódio e de lipídios. Os instrumentos utilizados para esta finalidade foram as modificações nas etapas e formas de preparos, assim como a inclusão de frutas e hortaliças nas diferentes receitas.

A medida se justifica, quando se percebe a culinária nordestina distante dos preceitos de uma alimentação saudável. Quando se remete a cultura alimentar nordestina, a tendência é imaginar os excessos, principalmente de lipídeos. Num primeiro momento tal pré-conceito não está errado, mas ao se compararem os preparos típicos nordestinos aos hábitos alimentares nas demais regiões brasileiras chega-se a uma conclusão unânime: os preparos, de todas essas regiões, são excessivos tanto em lipídios quanto em sódio e em açúcar.

Este fato se comprova por meio de pesquisas, onde receitas regionais brasileiras revelam-se com conteúdo lipídico superior as recomendações da OMS (2002). No 
entanto, a região nordestina aparece como a terceira posição em relação a conteúdos de gordura elevados (GINANI, 2004 e BOTELHO, 2006).

\subsection{LIPÍDIOS, SÓDIO E AÇÚCAR: FUNCIONALIDADE} GASTRONÔMICA

Os lipídios têm suas funções muito bem definidas no organismo humano. São importantes não apenas pelo seu valor energético, mas também pelo transporte de vitaminas lipossolúveis, ácidos graxos essenciais e responsáveis pela estrutura das membranas celulares. São responsáveis, também, pela produção de dois ácidos graxos importantes para o homem: o linoléico e o linolênico, uma vez que o organismo humano não é capaz e produzir as enzimas necessárias para sua produção. Tais substâncias são responsáveis por importantes funções fisiológicas como a contração do útero e o controle da pressão sangüínea (ARAÚJO et al, 2007).

No meio culinário, o uso da gordura interfere diretamente na cor, brilho, elasticidade, determinando ainda a aparência, textura e sabor (GINANI, 2004). Para Ornellas (1988), os lipídios são excelentes condutores de calor, dourando alimentos que foram cozidos, dourando sua superfície.

O alto teor de sódio é um dos fatores que resultam na complexa discussão sobre o controle da saúde pública. Evidencia-se que, aliado à ausência de atividades físicas diárias, estresse e tabagismo o consumo excessivo desse elemento químico, numa dieta desbalanceada, pobre em frutas e hortaliças e rica em alimentos industrializados, com alto teor de gordura e sódio, parece ser preditora de causadores no aumento da morbilidade cardiovascular, sendo amplamente discutido e pesquisado no meio (MOLINA et al, 2003). 
De acordo com dados populacionais publicados no relatório da Análise da Estratégia Global para Alimentação, Atividade Física e Saúde (OMS, 2002) sugerem que uma redução de $100 \mathrm{mmol} /$ dia de sódio está associada com diferenças na pressão sistólica de 5 mmHg (15-19 anos) e 10mmHg (60-69 anos). Estima-se que a redução de $50 \mathrm{mmol} /$ dia poderia levar a uma redução de $50 \%$ no número de indivíduos com necessidade de tratamento anti-hipertensivo, $22 \%$ no número de mortes por AVE (acidente vascular encefálico) e $16 \%$ no número de mortes por doenças coronarianas, sugerindo um ideal de $5 \mathrm{~g}$ de cloreto de sódio, por dia, para a prevenção de determinadas patologias.

O cloreto de sódio, do ponto de vista fisiológico, é uma molécula sápida que estimula os receptores das papilas gustativas que suprime o sabor que o acompanha ou não tem efeito nenhum sobre ele. Em termos gerais, o sal tem o poder de "mascarar" os sabores amargos do alimento, realçando os mais agradáveis (ATALA, 2008).

Utilizado como técnica de conservação de alimentos, o sal teve essa finalidade iniciada no período das grandes navegações européias, passando seu legado, no caso da formação gastronômica brasileira aos bandeirantes que desbravavam o interior do país, buscando mais uma forma de enviar um retorno financeiro à Coroa portuguesa (SENAC,2000).

Dentro de um dos compostos orgânicos encontrados em maior quantidade na natureza, os Carboidratos são divididos em Simples e Complexos. Juntamente com as proteínas, formam os principais constituintes do organismo vivo, sendo a mais abundante e mais econômica fonte de energia para o homem (ARAÚJO et al, 2007). 
Obtido a partir da cana de açúcar e da beterraba, o açúcar foi, por muito tempo, considerado ouro branco, sendo tão valioso a ponto de ser guardado em cofres, motivando guerras e sendo oferecido como dote aos novos maridos (FREYRE, 1997).

Mas a poesia do açúcar está sendo, gradativamente, deixada de lado desde que o conceito de Jenkins e cols., em 1981, foi adotado: o índice glicêmico. Tal conceito veio caracterizar a velocidade com que o organismo absorve os carboidratos e a resposta metabólica após as refeições, sendo considerada uma extensão da hipótese de fibra dietética, afirmando que a lenta absorção de nutrientes de alguns alimentos era sinônima de saúde. Não só a composição química, mas o tamanho das partículas e o seu processamento poderão influenciar na velocidade de absorção dos carboidratos (SARTORELLI, 2006).

O trabalho realizado por Sartorelli et.al (2006) propõe uma alimentação rica em fibras para na prevenção dos elevados picos de índice glicêmico como forma de prevenção para os malefícios causados pelos carboidratos simples. Sugere ainda o consumo de alimentos integrais e uma dieta rica em frutas e hortaliças. 


\section{MATERIAIS E MÉTODOS}

A pesquisa apresentada é de caráter exploratório qualitativo, classificada por Diehl e Tatim (2004) e dividida em duas etapas: 1) a seleção das receitas nordestinas com maior índice de repetição; 2) Testagem, adequação nutricional e elaboração das fichas técnicas.

\subsection{LEVANTAMENTO DAS RECEITAS}

Nessa etapa foram levantadas as receitas nordestinas de maior relevância. Estas foram selecionadas, com o apoio do Ministério da Saúde, de documentos enviados por diversas Secretarias de Saúde Municipais. Foram pesquisadas também receitas disponíveis na literatura comercial como é o caso do Larousse da cozinha Brasileira (CHAVES e FREIXA, 2007), Viagem Gastronômica através do Brasil (FERNANDES, 2002), dentre outros. Utilizou-se como critérios para selecionar os preparos a freqüência com que apareciam, sendo necessário o aparecimento em duas ou mais publicações para serem selecionadas, e a possível inserção de frutas e hortaliças sem prejudicar a imagem cultural da receita.

Foram, também, criados e desenvolvidos alguns preparos que utilizavam os ingredientes da região como base, dentre eles: mandioca, umbu, fubá de milho, abóbora (moranga), vinagreira, joão gomes, agrião cenoura, batatas - inglesa e doce, maxixe, quiabo, palma, chuchu, inhame, banana-da-terra, maturi, maracujá mamão-verde e charque, sempre levando em consideração aspectos financeiros e culturais.

Os preparos foram divididos em grupos tais como:

Grupo 1: Desjejum, Colação e Lanches / Grupo 2: Pratos Principais /Grupo 3: Acompanhamentos /Grupo 4: Guarnições /Grupo 5: Entrada /Grupo 6: Sobremesa 
A Figura 1 ilustra as quantidades e distribuição das receitas nordestinas selecionadas, em relação ao atendimento a todos os períodos de uma alimentação regular. A seleção de receitas está descrita na Tabela 1.

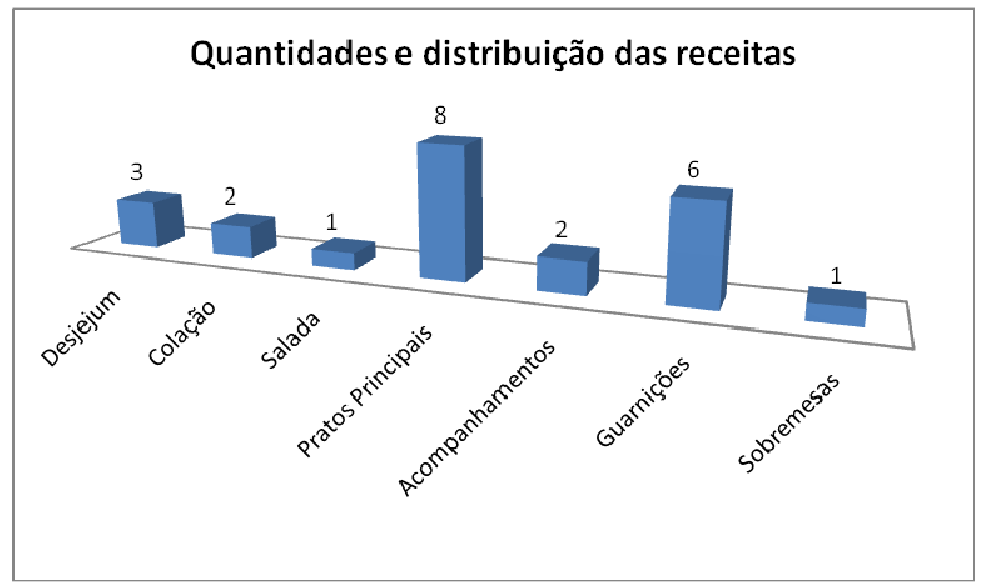

Figura 1: Quantidades e distribuição das receitas nordestinas selecionadas.

Tabela 1: Seleção do cardápio com os tipos e as receitas.

\begin{tabular}{ll}
\hline Tipo & Preparo \\
\hline Desjejum & $\bullet$ Pão de mandioca \\
& $\bullet$ Pão de abóbora \\
& $\bullet$ Umbuzada \\
& $\bullet$ Bolo de fubá \\
& $\bullet$ Salada de feijão fradinho com molho de \\
& cheiro verde \\
& $\bullet$ Escondidinho de abóbora com charque \\
& $\bullet$ Bobó do maranhão \\
& $\bullet$ Feijoada pernambucana \\
& $\bullet$ Rabada com agrião \\
& $\bullet$ Camarão com chuchu \\
& $\bullet$ Peixada alagoana \\
& $\bullet$ Refogado de carne moída com palma \\
\hline
\end{tabular}


- Cozido maranhense

\begin{tabular}{|ll}
\hline Acompanhamentos & Rubacão \\
& $\bullet$ Arroz de cuxá \\
\hline Guarnições & $\bullet$ Refogado de maxixe \\
& $\bullet$ Vatapá de inhame \\
& $\bullet$ Farofa de banana com cenoura \\
& $\bullet$ Refogado de mamão verde \\
& $\bullet$ Frigideira de maturi \\
& $\bullet$ Paçoca de carne-seca com banana da \\
& terra \\
\hline Sobremesa & Tapioca com geléia de maracujá \\
\hline
\end{tabular}

\subsection{TESTES E ADEQUAÇÃO NUTRICIONAL DAS RECEITAS PROPOSTAS}

As receitas foram testadas no laboratório de técnica dietética da Universidade Brasília (UnB), no período de maio a junho de 2008. As modificações foram realizadas, levando-se em consideração o valor nutricional, origem dos ingredientes e adequação com o propósito da pesquisa: uma alimentação nordestina mais saudável. Todos os ingredientes foram listados, destacando-se os possíveis responsáveis pela inadequação nutricional, como excesso de gordura, açúcar ou sódio. Posteriormente, considerando-se a funcionalidade destes ingredientes, foram propostas substituições, para então serem realizados os testes. Outro aspecto observado foi a técnica de cocção empregada. No caso de frituras, utilizou-se técnicas de semelhante princípio, ou seja, emprego de calor seco, como assar e grelhar.

Durante esta etapa, foram elaboradas as Fichas Técnicas de Preparo de todas as receitas desenvolvidas. Com estes dados em mãos, foi realizada a análise de composição química utilizando-se o software dietWin Versão 2008. 


\section{RESULTADOS E DISCUSSÃO \\ 4.1 REDUÇÃO LIPÍDICA}

Nos pães e no bolo de fubá, pertencentes ao grupo 1, a principal redução foi na quantidade de óleo e de ovos dos preparos modificados e o acréscimo das duas hortaliças utilizadas. O óleo nas receitas confere a preparação maciez, umidade, controle de hidratação do glúten e elasticidade. A redução das quantidades padrão em relação à receita modificada foi de $75 \%, 50 \%$ e $10 \%$, respectivamente para o bolo de fubá, o pão de mandioca e o pão de abóbora (ARAÚJO et al, 2007).

O ovo, que possui função de unificação e coesão da massa, além de saborizar e amaciar graças à gordura contida na gema, foi reduzido em $50 \%$ no bolo de fubá, 50\% no pão de mandioca e 66\% no pão de abóbora (ARAÚJO et al, 2007).

Para compensar a redução destes ingredientes a abóbora e a mandioca tiveram um papel fundamental. As hortaliças citadas interagem com as moléculas de água, formaram géis e soluções viscosas com propriedades químicas favoráveis (ARAÚJO, et al 2007).

A umbuzada, no entanto, não apresentou um número redutor de lipídios considerável relevante para o trabalho. A porcentagem da modificação pode ser vista na Tabela 2 abaixo: 
Tabela 2: Comparação dos valores lipídicos das porções das preparações regionais nordestinas originais e modificadas.

\begin{tabular}{|c|c|c|c|c|c|}
\hline Tipo & Preparo & Porção & $\begin{array}{c}\text { Lip } \\
\text { original } \\
\text { (gr) }\end{array}$ & $\begin{array}{c}\text { Lip } \\
\text { modificad } \\
\text { o (gr) }\end{array}$ & $\begin{array}{c}\% \\
\text { redução }\end{array}$ \\
\hline Desjejum & $\begin{array}{l}\text { - Pão de mandioca } \\
\text { - Pão de abóbora }\end{array}$ & $\begin{array}{l}50 \mathrm{gr} \\
75 \mathrm{gr}\end{array}$ & $\begin{array}{l}5,17 \\
3,49\end{array}$ & $\begin{array}{l}3,71 \\
1,42\end{array}$ & $\begin{array}{l}28,24 \\
59,51\end{array}$ \\
\hline Colação & - Bolo de fubá & $60 \mathrm{gr}$ & 12,07 & 5,14 & 57,42 \\
\hline Pratos Principais & $\begin{array}{l}\text { - Escondidinho de abóbora } \\
\text { - Bobó do maranhense } \\
\text { - Camarão com chuchu } \\
\text { - Refogado de carne com palma } \\
\text { - Cozido maranhense }\end{array}$ & $\begin{array}{l}160 \mathrm{gr} \\
130 \mathrm{gr} \\
150 \mathrm{gr} \\
250 \mathrm{gr} \\
215 \mathrm{gr}\end{array}$ & $\begin{array}{r}11,41 \\
9,9 \\
5,8 \\
18,76 \\
6,56\end{array}$ & $\begin{array}{r}8,43 \\
0,75 \\
1,45 \\
10 \\
2,92\end{array}$ & $\begin{array}{c}26,12 \\
92,42 \\
75 \\
46,70 \\
55,49\end{array}$ \\
\hline Acompanhamentos & $\begin{array}{l}\text { - Rubacão } \\
\text { - Arroz de cuxá }\end{array}$ & $\begin{array}{l}150 \mathrm{gr} \\
90 \mathrm{gr}\end{array}$ & $\begin{array}{r}18,09 \\
6,22\end{array}$ & $\begin{array}{l}11,23 \\
4,10\end{array}$ & $\begin{array}{l}37,92 \\
34,08\end{array}$ \\
\hline Guarnições & $\begin{array}{l}\text { - Maxixada } \\
\text { - Vatapá de inhame } \\
\text { - Farofa de banana com } \\
\text { cenoura } \\
\text { - Refogado de mamão verde }\end{array}$ & $\begin{array}{l}81 \mathrm{gr} \\
54 \mathrm{gr} \\
80 \mathrm{gr} \\
85 \mathrm{gr}\end{array}$ & $\begin{array}{r}9,42 \\
8,45 \\
14,43 \\
3,98\end{array}$ & $\begin{array}{r}2,7 \\
1,79 \\
3,59 \\
0,25\end{array}$ & $\begin{array}{l}71,34 \\
78,82 \\
75,12 \\
93,72\end{array}$ \\
\hline
\end{tabular}

Para o grupo dos pratos principais observou-se uma redução lipídica de 26,12\% no escondidinho de abóbora, $92,42 \%$ no bobó maranhense, $75 \%$ no camarão com chuchu, $46,70 \%$ no refogado de carne com palma e 55,49\% no cozido maranhense, conforme a tabela 2 ilustra. A quantidade de gordura utilizada nas preparações, assim como outros ingredientes gordurosos foram reduzidos. Para compensar a ausência destes itens, importantes como veículo de sabor e responsáveis por atributos como brilho, foram aumentas as quantidades de hortaliças na receita. Pretendeu-se com estas 
práticas o incremento de fibras, micronutrientes e redução de calorias, obtidas pela gordura, e sódio.

Outro aspecto importante que contribui para a confecção das receitas modificadas, foi a possibilidade do uso de utensílios de cozinha apropriados, como panelas de teflon. Desta forma, técnicas de cocção que utilizam calor seco com pouca ou nenhuma gordura, como grelhar, refogar, assar, foram aplicadas com sucesso, e conseqüente redução do valor lipídico dos preparos. O resultado foi, aparentemente, satisfatório e será foco de uma pesquisa maior na aceitabilidade de tais receitas, com aplicação de técnicas apropriadas de análise sensorial.

Técnicas como o uso de fervura prévia, ou assar carnes em grelhas, desprezando-se a gordura excedente liberada, também foram utilizadas. Contudo, nestes casos, como os ingredientes permaneciam os mesmos, não houve a possibilidade de aferição das reduções por meio de tabelas de composição química de alimentos. O fato se deve pela não mensuração da gordura liberada, para subtração posterior dos valores encontrados nas tabelas. Para isso, seria, portanto, necessária uma análise química em laboratório para quantificar as reduções reais alcançadas. O Quadro 1 mostra três pratos que exemplificam tal fato.

No primeiro, uma feijoada pernambucana, conhecida no nordeste por acrescentar uma série de hortaliças (abóbora, batata doce, maxixe, batata inglesa, quiabo, couve e chuchu) diferente da preparada no sudeste. Neste caso, para a feijoada pernambucana, as carnes foram cozidas e com isso acredita-se ter reduzido tanto parte da gordura como do teor de sal com o aquecimento. 
Na rabada, preparo à base de uma carne mais acessível financeiramente, mas com excessivo valor lipídico, foi retirada a gordura aparente com o auxilio de uma faca. Posteriormente, a carne foi assada (calor seco) com a finalidade de liquefazer a gordura e desprezá-la em seguida. Utilizando-se desses dois processos, reduziu-se o peso inicial de 1060 gramas para 800 gramas, acreditando-se maior parte dessa redução de gordura.

A paçoca de carne teve seu processo de cocção beneficiado pelo calor seco, tendo sua fabricação drasticamente alterada. Ao invés da fritura, onde o alimento absorveria parte da gordura, a transmissão do calor por convecção dispensa o uso da gordura para cozinhar o alimento. Inicialmente a carne foi cozida na pressão com o objetivo de abrandar as fibras para que pudesse ser desfiada. Como a preparação original era frita, o resultado refletia características do método, ou seja, a absorção da gordura pelo alimento aumentava o valor lipídico. Para que então fosse alcançado o resultado similar, após se desfiada a carne foi assada. O resultado final foi uma paçoca com características organolépticas muito próximas às técnicas originais utilizadas, mas com o ganho salutar da redução lipídica (ARAÚJO et al, 2007).

Quadro1: Ingredientes e técnicas de cocção

\begin{tabular}{|c|c|c|c|}
\hline Receitas & Ingredientes & \multicolumn{2}{|c|}{ Técnicas de cocção } \\
\hline & - costela defumada (113gr) & Padrão & Modificada \\
\hline $\begin{array}{c}\text { Feijoada } \\
\text { Pernambucana }\end{array}$ & $\begin{array}{l}\text { - } \text { porco, rabo, salgado (234gr) } \\
\text { - bacon (187gr) } \\
\text { - linguiça calabresa (240gr) } \\
\text { - porco, orelha, salgada (218gr) } \\
\text { - chuchu (293gr) } \\
\text { - } \text { abóbora (289gr) } \\
\text { - cenoura (98gr) } \\
\text { - maxixe (166gr) } \\
\text { - batata, inglesa (215gr) } \\
\text { - batata, doce (316gr) } \\
\text { - cebola (100gr) } \\
\text { - tomate (100gr) } \\
\text { - } \text { alho (15gr) } \\
\text { - pimentão, verde (50gr) } \\
\text { - quiabo (120gr) } \\
\text { - pimenta do reino (2gr) }\end{array}$ & $\begin{array}{l}\text { Todas as carnes } \\
\text { são adicionadas ao } \\
\text { preparo somente } \\
\text { lavadas para a } \\
\text { retirada de sal. }\end{array}$ & $\begin{array}{c}\text { As carnes } \\
\text { dessalgadas e } \\
\text { cozidas (Calor } \\
\text { úmido). Com isso } \\
\text { foi retirado tanto o } \\
\text { excesso de sal } \\
\text { como de lipídeo }\end{array}$ \\
\hline
\end{tabular}




\begin{tabular}{|c|c|c|c|}
\hline & $\begin{array}{l}\text { - feijão mulatinho (400gr) } \\
\text { - louro (2gr) } \\
\text { - pé de porco (234gr) }\end{array}$ & & \\
\hline Rabada & $\begin{array}{l}\text { - Rabo de boi (1060gr) } \\
\text { - Cebola (307gr) } \\
\text { - Alho (40gr) } \\
\text { - Louro (4gr) } \\
\text { - Corante (colorau) (7gr) } \\
\text { - Sal (5gr) } \\
\text { - Pimenta (10gr) } \\
\text { - Agrião (310gr) }\end{array}$ & $\begin{array}{c}\text { Todos os } \\
\text { ingredientes, com } \\
\text { exceção do agrião, } \\
\text { são posto na } \\
\text { panela de pressão } \\
\text { e cozidos. }\end{array}$ & $\begin{array}{l}\text { Foi retirada a } \\
\text { gordura aparente } \\
\text { com a faca, } \\
\text { reduzindo já o } \\
\text { peso para } 880 \mathrm{gr} \text {. } \\
\text { Em seguida a } \\
\text { carne foi assada } \\
\text { (calor seco) para } \\
\text { retirar ainda mais } \\
\text { a gordura. Com } \\
\text { isso chegou-se a } \\
\text { 800gr antes de } \\
\text { continuar a } \\
\text { cocção. }\end{array}$ \\
\hline Paçoca de carne & $\begin{array}{l}\text { - Charque (170gr) } \\
\text { - Cebola (60gr) } \\
\text { - Farinha de mandioca (150gr) } \\
\text { - Óleo de soja (10ml) } \\
\text { - Banana da terra (170gr) }\end{array}$ & $\begin{array}{l}\text { A carne é frita e } \\
\text { pilada (desfiada } \\
\text { em pilão) }\end{array}$ & $\begin{array}{l}\text { A carne foi assada } \\
\text { (calor seco) e } \\
\text { depois pilada. }\end{array}$ \\
\hline
\end{tabular}

Algumas receitas modificadas do grupo das guarnições, como o caso do vatapá de inhame, prato tipicamente baiano, a modificação foi mais significativa. O uso do azeite de dendê, ingrediente largamente utilizado na maioria dos pratos desse estado, é feito de maneira exagerada. $\mathrm{O}$ uso na receita original era de $30 \mathrm{ml}$, sendo reduzido para $5 \mathrm{ml}$, acreditando-se manter o sabor do preparo. Como qualquer outro azeite, é necessária uma quantidade pequena, pois o seu papel é complementar o sabor do prato.

$\mathrm{Na}$ farofa de banana-da-terra foi acrescentada a cenoura ralada. Além de reduzir a quantidade de lipídeos, o objetivo foi aumentar o valor nutritivo e equilibrar as texturas do preparo, uma vez que a cenoura, acrescentada in natura, oferecia um contraponto de resistência à banana, melhorando a palatabilidade do preparo. $\mathrm{O}$ resultado foi reduzir a quantidade de ingredientes lipídicos na mesma porção ofertada, uma vez, que neste caso a porção foi acrescida de hortaliças. 


\subsection{REDUÇÃO DE SAL ADICIONADO}

Em todos os preparos propostos no trabalho, a redução mínima de sal adicionado foi de $50 \%$, podendo chegar até $100 \%$, como mostra a Tabela 3 . O sabor resultante foi aparentemente satisfatório graças ao aumento no uso de outros temperos como alho, especiarias e ervas frescas como o coentro e a cebolinha. Contudo sabe-se que a análise sensorial seria indispensável para confirmação do fato.

A grande dificuldade na comparação das receitas foi a não utilização de uma medida padrão para o uso do sal. Termos populares como "uma pitada", ou "a gosto", ou até "quanto necessário", foram largamente utilizados, impossibilitando a comparação. Alguns exemplos desses preparos são: paçoca de carne seca com banana, rubacão, escondidinho de abóbora, pão de abóbora e no refogado de mamão verde. Portanto, o objetivo foi utilizar as recomendações nutricionais adequados

De acordo com a OMS (2002), 5 gramas de sal adicionado é o recomendado como somatório de todas as refeições diárias e deve ser distribuído, segundo o PAT (Programa de Alimentação do Trabalhador) do Ministério do Trabalho, para uma dieta de 2000Kcal da seguinte forma: $20 \%$ (Desjejum), 5\% (Colação), 35\% (Almoço), 10\% (Lanche) e 30\% (Jantar), como mostra a Tabela 3. Deve-se levar em consideração que as refeições são compostas de mais de um preparo. 
Tabela 3: Comparação da quantidade de $\mathrm{NaCl}$ adicionado aos preparos para as amostras padrão e modificadas e a quantidade na porção comparando-se com as recomendações do Ministério da Saúde.

\begin{tabular}{|c|c|c|c|c|c|c|}
\hline Grupo & Receita & $\begin{array}{c}\mathrm{NaCl} \\
\text { padrão } \\
(\mathrm{gr})\end{array}$ & $\begin{array}{c}\mathrm{NaCl} \\
\text { modifica } \\
\text { do }(\mathrm{gr})\end{array}$ & $\begin{array}{l}(\%) \text { de } \\
\text { redução }\end{array}$ & $\begin{array}{c}\text { NaCl } \\
\text { (porção } \\
\text { modificada) }\end{array}$ & $\begin{array}{l}\text { Recomenda } \\
\text { ção MS dia }\end{array}$ \\
\hline \multirow{2}{*}{ Desjejum } & Pão de mandioca & 12 & 6 & $50 \%$ & $0,2 \mathrm{~g}$ & \\
\hline & Pão de abóbora & 30 & 10 & $66,7 \%$ & $0,7 \mathrm{~g}$ & \\
\hline \multirow{6}{*}{ Almoço } & $\begin{array}{l}\text { Vatapá de } \\
\text { inhame }\end{array}$ & 20 & 5 & $75 \%$ & $0,9 \mathrm{~g}$ & \\
\hline & $\begin{array}{l}\text { Rabada com } \\
\text { agrião }\end{array}$ & 20 & 5 & $75 \%$ & $0,4 \mathrm{~g}$ & \\
\hline & $\begin{array}{l}\text { Feijoada } \\
\text { Pernambucana }\end{array}$ & 15 & 0 & $100 \%$ & & \multirow{8}{*}{$5 g r$} \\
\hline & $\begin{array}{l}\text { Cozido } \\
\text { maranhense }\end{array}$ & 25 & 5 & $80 \%$ & $0,5 \mathrm{~g}$ & \\
\hline & $\begin{array}{l}\text { Bobó } \\
\text { maranhense }\end{array}$ & 5 & 0 & $100 \%$ & & \\
\hline & $\begin{array}{l}\text { Camarão com } \\
\text { chuchu }\end{array}$ & 10 & 3 & $70 \%$ & $0,7 \mathrm{~g}$ & \\
\hline \multirow{2}{*}{ Guarnição } & $\begin{array}{l}\text { Refogado de } \\
\text { mamão verde }\end{array}$ & 10 & 3 & $70 \%$ & $0,4 \mathrm{~g}$ & \\
\hline & $\begin{array}{l}\text { Refogado de } \\
\text { maxixe }\end{array}$ & 8 & 3 & $72,5 \%$ & $0,6 \mathrm{~g}$ & \\
\hline \multirow{2}{*}{$\begin{array}{l}\text { Acompanha- } \\
\text { mentos }\end{array}$} & Arroz de cuxá & 10 & 2 & $80 \%$ & $0,2 \mathrm{~g}$ & \\
\hline & Rubacão & 10 & 5 & $50 \%$ & $0,4 \mathrm{~g}$ & \\
\hline
\end{tabular}




\subsection{REDUÇÃO DE AÇÚCAR}

A Tabela 4 abaixo mostra a comparação da quantidade de açúcar adicionado aos preparos. No caso da geléia de maracujá, além da redução significativa da quantidade de açúcar, fez valer as propriedades gelificantes da pectina contida na casca da própria fruta, obtendo-se a consistência mesmo sem a grande quantidade de açúcar. O percentual normalmente indicado nas receitas de geléia é de 50\% (BOTELHO, 2005). Contudo utilizou-se $50 \%$ da quantidade original do preparo. O uso de açúcar na geléia se justifica pela propriedade de higroscopicidade, solubilidade e dulçor, sendo atingida uma característica organoléptica próxima à receita original.

No bolo a ocorrência da cor superficial e textura são obtidas pela caramelização e capacidade de interferência na formação do glúten, respectivamente, conseqüentes do uso de açúcar.

Tabela 4: Comparação da quantidade de açúcar adicionado aos preparos.

\begin{tabular}{lccc}
\hline \multicolumn{1}{c}{ Receita } & $\begin{array}{c}\text { Valor de CHO simples } \\
\text { padrão (gr) }\end{array}$ & $\begin{array}{c}\text { Valor de CHO } \\
\text { modificado (gr) }\end{array}$ & $\begin{array}{c}\text { Porcentagem da } \\
\text { redução }(\%)\end{array}$ \\
\hline Bolo de Fubá & 250 & 150 & $40 \%$ \\
$\begin{array}{l}\text { Geléia de } \\
\text { maracujá }\end{array}$ & 150 & 80 & $47 \%$ \\
\hline
\end{tabular}




\section{CONCLUSÃO}

Notou-se no trabalho que tanto os lipídios, como o sódio adicionado e o açúcar têm importância culinária e para a redução de suas quantidades, são necessários conhecimentos específicos sobre técnica dietética. A utilização de frutas e hortaliças pode ser uma alternativa para a obtenção de resultados sensoriais favoráveis, uma vez que atributos com sabor, textura, cor, podem ser conferidos com o uso destes ingredientes. A razão se dá pela presença de substâncias compatíveis com a funcionalidade dos ingredientes citados, como foi observado nas receitas propostas.

Por outro lado, o consumo de frutas e hortaliças na dieta tende a prevenir as DCNT's. No entanto, deve-se considerar não somente uma Alimentação Saudável, mas um conjunto de novos hábitos que devem fazer parte do cotidiano, como a associação de uma boa alimentação com atividades físicas diárias.

O Nordeste brasileiro apresenta grande diversidade de frutas, muitas vezes subutilizadas pela população. Experimentos que busquem por alternativas para o aproveitamento integral dos vegetais disponíveis na região devem ser estimulados. Os resultados demonstram a relevância do tema, e sugerem maiores estudos para complementação dos dados obtidos.

Desta forma, será possível a viabilização de programas para a promoção da saúde que vislumbrem não somente aspectos relativos a redução de itens da alimentação, mas a inclusão de ingredientes capazes de tornar a rotina alimentar da população mais aprazível. 


\section{REFERÊNCIAS BIBLIOGRÁFICAS}

BARROS, R., FONTINELE, R, SEYFFARTH, A. Intervenção nutricional em grupo de moradores pelo Programa Família Saudável. Com. Ciências Saúde.

2007;18(3):207-214.

SENAC. DN. Multissabores - a formação da gastronomia brasileira. / Nick Zarvos; Carlos Augusto da Silva Ditadi. Rio de Janeiro: Ed. Senac Nacional, 2000.

ROMIO, Eda. 500 anos de sabor. São Paulo: ER Comunicações, 2000.

CASCUDO, Luiz da Câmara. História da alimentação no Brasil - 3 ed - São Paulo: Global, 2004.

ABREU, Edeli Simoni et al. Alimentação mundial - uma reflexão sobre a História. Saúde e Sociedade 10(2):3-14, 2001.

FREYRE, Gilberto. Açúcar: Uma sociologia do doce, com receitas de bolos e doces do Nordeste do Brasil. São Paulo: Cia. das Letras, 1997.

SARTORELLI, Daniela S. and CARDOSO, Marly A. Associação entre carboidratos da dieta habitual e diabetes mellitus tipo 2: evidências epidemiológicas. Arq Bras Endocrinol Metab, June 2006, vol.50, no.3, p.415-426. ISSN 0004-2730.

NEUMANN, Africa Isabel de la Cruz Perez, SHIRASSU, Mirian Matsura and FISBERG, Regina Mara. Consumo de alimentos de risco e proteção para doenças cardiovasculares entre funcionários públicos. Rev. Nutr., Jan./Feb. 2006, vol.19, no.1, p.19-28. ISSN 1415-5273.

OMS - World Health Organization. Food and Agriculture Organization. Joint WHO/FAO expert consultation. Diet, nutrition and the prevention of chronic diseases. Geneva: WHO/FAO; 2002

BRASIL. Análise da Estratégia Global para Alimentação Saudável, Atividade

Física e Saúde. Documento realizado pelo grupo técnico assessor instituído pela portaria do Ministério da Saúde n. 596, de 8 de abril de 2004. Brasília, 2004 b.

POULAIN, JP. Sociologias da Alimentação. Florianópolis: Editora da UFSC, 2004.

CARNEIRO, H. Comida e Sociedade: uma história da alimentação. Rio de Janeiro: Campus, 2003.

FERNANDES, C. Viagem Gastronômica através do Brasil. 3. Ed. São Paulo: Editora SENAC São Paulo: 2002.

ARAÚJO, W.M.C. Alquimia dos Alimentos. Distrito Federal: Editora SENAC, 2007. 
ORNELlAS, L.H. Técnica dietética. Seleção e preparo de alimentos. 5.ed. São Paulo: Atheneu, 1988

ATALA, A. Com unhas dentes e cuca. São Paulo: Senac São Paulo, 2008 


\section{FICHA TÉCNICA DE PREPARO}

\section{Tipo de Produto (Grupo): Desjejum}

Item: Pão de mandioca

Rendimento: $1500 \mathrm{~g}$

Nível de complexidade: Baixo

Porção: $50 \mathrm{~g}$

\begin{tabular}{|l|c|c|c|}
\hline \multicolumn{1}{|c|}{ Ingredientes } & PB $(\mathbf{g}, \mathbf{m l})$ & PL $\mathbf{( g , ~} \mathbf{~ m l})$ & FC \\
\hline Mandioca & 340,00 & 295,00 & 1,15 \\
\hline Fermento fresco & 30,00 & 30,00 & 1,00 \\
\hline Ovo & 110,00 & 110,00 & 1,00 \\
\hline Óleo de soja & 35,00 & 35,00 & 1,00 \\
\hline Farinha de trigo & 200,00 & 200,00 & 1,00 \\
\hline Sal & 6,00 & 6,00 & 1,00 \\
\hline Açúcar & 3,00 & 3,00 & 1,00 \\
\hline
\end{tabular}

Modo de preparo: Descasque e cozinhe a abóbora, guardando a água do cozimento e fazendo um purê. Trabalhe o fermento com o açúcar, 50 gramas de farinha de tirgo e $20 \mathrm{ml}$ da água do cozimento. DEixe que dobre de tamanho. Em seguida acrescente ao purê, o ovo, o óleo de soja, o sal, a massa fermentada, e adicione a farinha aos poucos.

(Dependendo da abóbora e da farinha de trigo, essas quantidades tendem a ser vaviáveis.) Sove a massa até que esteja bem lisa. Deixe-a fermentar mais uma vez para dobrar o tamanho e faça bolinhas. Unte uma fôma com um fio de óleo, enfarinhe e deixe que os pãezinhos dobream mais uma vez de tamanho. Aqueça o forno a 180 graus e asse-os até que estejam dourados.

INFORMAÇÃ̃O NUTRICIONAL - Porção de: $50 \mathrm{~g}$

Valor energético: 116,66kcal

Proteínas: $3,17 \mathrm{~g}$

Carboidratos: $17,62 \mathrm{~g}$

Lipídios: 3,71g 


\section{FICHA TÉCNICA DE PREPARO}

\section{Tipo de Produto (Grupo): Desjejum}

\section{Item: Pão de abóbora}

Rendimento: $1105 \mathrm{~g}$

Porção: $75 \mathrm{~g}$

Nível de complexidade: Baixo

Porção (Medida Caseira): 1 pãozinho

\begin{tabular}{|l|c|c|c|}
\hline \multicolumn{1}{|c|}{ Ingredientes } & PB $\mathbf{( g , m l})$ & PL $\mathbf{( g , ~} \mathbf{~ m l})$ & FC \\
\hline Abóbora & 835,00 & 555,00 & 1,50 \\
\hline Ovo & 55,00 & 55,00 & 1,00 \\
\hline Farinha de trigo & 800,00 & 800,00 & 1,00 \\
\hline Óleo de soja & 5,00 & 5,00 & 1,00 \\
\hline Fermento seco & 10,00 & 10,00 & 1,00 \\
\hline Açúcar & 60,00 & 60,00 & 1,00 \\
\hline Sal & 10,00 & 10,00 & 1,00 \\
\hline
\end{tabular}

Modo de preparo: Descasque, retire o talo central e cozinhe a mandioca com água., fazendo um purê em seguida e mantendo a água do cozimento. Dissolva o fermento com açúcar e acrescente 30 gramas de farinha de trigo e deixe fermentar por aproximedamente 30 minutos. Em seguida acrescente o ovo, o purê de mandioca, o óleo e o sal. Sove a massa até que esteja bem lisa. e deixe fermentar novamente atéque dobre o tamanho. Aqueça o forno a 180 graus.

Depois de fermentada, faça pequenas bolas e coloque numa fôma enfarinhada. Deixe fermentar novamente e leve ao forno para assar.

INFORMAÇÃO NUTRICIONAL - Porção de: $75 \mathrm{~g}$

Valor energético: $165,01 \mathrm{kcal}$

Proteínas: 5,41g

Carboidratos: $32,66 \mathrm{~g}$

Lipídios: 1,42g 


\section{FICHA TÉCNICA DE PREPARO}

\section{Tipo de Produto (Grupo): Colação}

\section{Item: Umbuzada}

Rendimento: $600 \mathrm{ml}$

Porção: 200ml

Nível de complexidade: Baixo

Porção (Medida Caseira): 1 copo

\begin{tabular}{|l|c|c|c|}
\hline \multicolumn{1}{|c|}{ Ingredientes } & PB $\mathbf{( g , m l )}$ & PL $\mathbf{( g , ~ m l})$ & FC \\
\hline Umbu & 370,00 & 370,00 & 1,00 \\
\hline Leite desnatado & 500,00 & 500,00 & 1,00 \\
\hline Açúcar & 30,00 & 30,00 & 1,00 \\
\hline
\end{tabular}

Modo de preparo: Leve ao fogo todos os ingredientes, mexendo sempre para o leite não derramar. Quando ferver, desligue o fo go e deixe esfriar na própria panela. Em seguida retire os caroços do umbu e leve o restante ao liquidificador. OBS: Se estiver na época de colheita do umbu, quanto mais madura for a fruta, menos açúcar precisará para adoçar a ubuzada.

INFORMAÇÃO NUTRICIONAL - Porção de: $200 \mathrm{ml}$

Valor energético: $98,98 \mathrm{kcal}$

Proteínas: 4,60g

Carboidratos: $19,72 \mathrm{~g}$

Lipídios: $0,19 \mathrm{~g}$ 


\section{FICHA TÉCNICA DE PREPARO}

Tipo de Produto (Grupo): Colação

Item: Bolo de fubá

Rendimento: $770 \mathrm{~g} \quad$ Porção: $60 \mathrm{~g}$

Nível de complexidade: Baixo

Porção (Medida Caseira): 1 fatia

\begin{tabular}{|l|c|c|c|}
\hline \multicolumn{1}{|c|}{ Ingredientes } & PB $\mathbf{( g , m l})$ & PL $\mathbf{~ g , ~} \mathbf{~ m l})$ & FC \\
\hline Fubá de milho & 155,00 & 155,00 & 1,00 \\
\hline Milho verde & 210,00 & 210,00 & 1,00 \\
\hline Farinha de trigo & 100,00 & 100,00 & 1,00 \\
\hline Açúcar & 150,00 & 150,00 & 1,00 \\
\hline Óleo de soja & 50,00 & 50,00 & 1,00 \\
\hline Fermento em pó & 15,00 & 15,00 & 1,00 \\
\hline Ovo (gema) & 55,00 & 15,00 & 3,67 \\
\hline Ovo (clara) & 110,00 & 80,00 & 1,38 \\
\hline Água & 130,00 & 130,00 & 1,00 \\
\hline Canela em pó & 10,00 & 10,00 & 1,00 \\
\hline
\end{tabular}

Modo de preparo: Coloque os ingredientes no liquidificador, com excessão da canela e um pouco do açúcar. Bata até que esteja homogêneo e despeje numa fôrma untada e polvilhada com a mistura de açúcar e canela. Leve ao fôrno pré-aquecido a 180 graus.

\section{INFORMAÇÃO NUTRICIONAL - Porção de: 60g}

Valor energético: $178,63 \mathrm{kcal}$

Proteínas: $2,97 \mathrm{~g}$

Carboidratos: $30,08 \mathrm{~g}$

Lipídios: 5,14g 


\section{FICHA TÉCNICA DE PREPARO}

Tipo de Produto (Grupo): Salada

Item: Salada de feijão verde com molho de pimenta de cheiro

Rendimento: $755 \mathrm{~g}$

Porção: $100 \mathrm{~g}$

Nível de complexidade: Baixo

Porção (Medida Caseira): 2 colheres de sopa

\begin{tabular}{|c|c|c|c|}
\hline Ingredientes & PB (g,ml) & PL $(\mathrm{g}, \mathrm{ml})$ & FC \\
\hline Feijão de corda & 296,00 & 296,00 & 1,00 \\
\hline Cebola & & 60,00 & 0,00 \\
\hline Pimentão verde & & 50,00 & 0,00 \\
\hline \begin{tabular}{|l|} 
Tomate \\
\end{tabular} & & 140,00 & 0,00 \\
\hline Cebolinha & & 10,00 & 0,00 \\
\hline Abóbora & 280,00 & 200,00 & 1,40 \\
\hline Sal & 2,00 & 2,00 & 1,00 \\
\hline Água & 750,00 & 750,00 & 1,00 \\
\hline Alface & 14,00 & 13,00 & 1,08 \\
\hline \multicolumn{4}{|c|}{ Molho: } \\
\hline logurte desnatado & 200,00 & 200,00 & 1,00 \\
\hline Pimenta de cheiro & 30,00 & 20,00 & 1,50 \\
\hline Mel & 20,00 & 20,00 & 1,00 \\
\hline
\end{tabular}

Modo de preparo: Cozinhe o feijão de corda e reserve. Corte a abóbora em cubos pequenos e cozinhe. Corte os demais em cubos bem pequenos, acrescente o feijão, a abóbora e as folhas de alface rasgadas.

Molho: Retire as sementes da pimenta de cheiro e bata tudo no liquidificador. Sirva a salada e o molho à parte.

INFORMAÇÃO NUTRICIONAL - Porção de: $100 \mathrm{~g}$

Valor energético: $129,03 \mathrm{kcal}$

Proteínas: 7,42g

Carboidratos: $23,72 \mathrm{~g}$

Lipídios: 0,50g 


\section{FICHA TÉCNICA DE PREPARO}

Tipo de Produto (Grupo): Pratos Principais

Item: Escondidinho de abóbora com charque

Rendimento: 930g

Porção: $160 \mathrm{~g}$

Nível de complexidade: Baixo

Porção (Medida Caseira): 2 colheres de sopa

\begin{tabular}{|l|c|c|c|}
\hline \multicolumn{1}{|c|}{ Ingredientes } & PB $\mathbf{( g , m l )}$ & PL $\mathbf{( g , ~} \mathbf{~ m l})$ & FC \\
\hline Abóbora & 470,00 & 345,00 & 1,36 \\
\hline Charque & 285,00 & 200,00 & 1,43 \\
\hline Cebola & & 200,00 & \\
\hline Alho & & 15,00 & 1,00 \\
\hline Coentro & 10,00 & 10,00 & 1,00 \\
\hline Cebolinha & 10,00 & 10,00 & 1,00 \\
\hline Manteiga sem sal & 5,00 & 5,00 & 1,00 \\
\hline Mussarela & 20,00 & 20,00 & 1,00 \\
\hline Sal & 5,00 & 5,00 & 1,00 \\
\hline Pimenta do reino & 2,00 & 2,00 & \\
\hline
\end{tabular}

Modo de preparo: Retire, com a faca, toda gordura aparente da carne de charque. Cozinhe-a, trocando a água por aproximadamente 4 vezes. Na última troca de água, reserve-a para a cocção da abóbora já descascada, fazendo um purê assim que estiver cozida e enquanto ela está quente.

Refogue, na manteiga, a cebola, o alho e a carne já desfiada. Acrescente o coentro e a cebolinha e reserve.

Leve o purê de abóbora para o fogo para extrair o excesso de água.

Montagem: em um refratário, forre o fundo com o purê, acrescente o refogado de charque, e coloque outra camada do purê. Finalize com o queijo mussarela e leve ao forno pré-aquecido para gratinar (derreter e dourar o queijo).

INFORMAÇÃO NUTRICIONAL - Porção de: $160 \mathrm{~g}$

Valor energético: 146,13kcal

Proteínas: 11,56g

Carboidratos: 6,01g

Lipídios: $8,43 \mathrm{~g}$ 


\section{FICHA TÉCNICA DE PREPARO}

\section{Tipo de Produto (Grupo): Pratos Principais}

Item: Bobó maranhense

Rendimento: $840 \mathrm{~g}$

Porção: $130 \mathrm{~g}$

Nível de complexidade: Baixo

Porção (Medida Caseira): 3 colheres de sopa

\begin{tabular}{|l|c|c|c|}
\hline \multicolumn{1}{|c|}{ Ingredientes } & PB $(\mathbf{g , m l})$ & PL $\mathbf{( g , ~} \mathbf{~ m l})$ & FC \\
\hline Vinagreira cozida & 60,00 & 60,00 & 1,00 \\
\hline João gomes & 60,00 & 60,00 & 1,00 \\
\hline Quiabo & 241,00 & 200,00 & 1,21 \\
\hline Pimentão verde & & 30,00 & \\
\hline Cebola & & 60,00 & \\
\hline Alho & & 7,00 & \\
\hline Tomate & & 70,00 & \\
\hline Óleo de soja & 2,00 & 2,00 & 2,00 \\
\hline Camarão seco & 200,00 & 200,00 & 1,00 \\
\hline
\end{tabular}

Modo de preparo: Retire o excesso de sal do camarão em água corrente. Refogue, com o óleo de soja, a cebola, o alho e o pimentão verde. Em seguida acrescente o camarão seco, a vinagreira, o joão gomes e o quiabo. Cubra o preparo com água e cozinhe até que o quiabo esteja na consistência desejada.

OBS: Corte o quiabo de maneira que fique bem pequeno ou processe-o junto com o camarão.

INFORMAÇÃO NUTRICIONAL - Porção de: $130 \mathrm{~g}$

Valor energético: 49,09kcal

Proteínas: 5,73g

Carboidratos: $4,84 \mathrm{~g}$

Lipídios: 0,75g 


\section{FICHA TÉCNICA DE PREPARO}

Tipo de Produto (Grupo): Pratos Principais Item: Feijoada Pernambucana

Rendimento: $1830 \mathrm{~g}$

Nível de complexidade: Médio

\begin{tabular}{|l|c|c|c|}
\hline \multicolumn{1}{|c|}{ Ingredientes } & PB $(\mathbf{g , m l})$ & PL $(\mathbf{g}, \mathbf{~ m l})$ & FC \\
\hline costela & 113,00 & 113,00 & 1,00 \\
\hline pé de porco & 234,00 & 234,00 & 1,00 \\
\hline bacon & 187,00 & 187,00 & 1,00 \\
\hline calabresa & 240,00 & 240,00 & 1,00 \\
\hline orelha & 218,00 & 218,00 & 1,23 \\
\hline chuchu & 360,00 & 293,00 & 1,51 \\
\hline abóbora & 435,00 & 289,00 & 1,21 \\
\hline cenoura & 119,00 & 98,00 & 1,25 \\
\hline mexixe & 207,00 & 166,00 & 1,21 \\
\hline batata inglesa & 260,00 & 215,00 & 1,24 \\
\hline batata doce & 391,00 & 316,00 & \\
\hline cebola & & 100,00 & \\
\hline tomate & & 100,00 & 1,17 \\
\hline alho & & 15,00 & 1,00 \\
\hline pimentão & & 50,00 & 1,00 \\
\hline quiabo & 140,00 & 120,00 & 1,00 \\
\hline pimenta do reino & 2,00 & 2,00 & \\
\hline louro seco & 2,00 & 2,00 & \\
\hline feijão mulatinho & 400,00 & 400,00 & \\
\hline
\end{tabular}

Modo de preparo: Refogue o bacon cebola, o alho, o pimentão e o tomate. Acrescente a folha de louro, o feijão e cozinhe. Dessalgue todas as carnes trocando a água aproximadamente 5 vezes. Acrescente essas carnes ao com o pé e a orelha. Acrescente o restante das carnes e os legumes mais duros, continuando o cozimento. Em seguida acrescente os legumes menos resistentes.

INFORMAÇÃO NUTRICIONAL - Porção de: $250 \mathrm{~g}$

Valor energético: $463,88 \mathrm{kcal}$

Proteínas: $23,62 \mathrm{~g}$

Carboidratos: $31,70 \mathrm{~g}$

Lipídios: 26,96g 


\section{FICHA TÉCNICA DE PREPARO}

Tipo de Produto (Grupo): Pratos Principais Item: Camarão com chuchu

Rendimento: $600 \mathrm{~g}$ Porção: $150 \mathrm{~g}$

Nível de complexidade: Baixo Porção (Medida Caseira): 2 colheres de sopa

\begin{tabular}{|l|c|c|c|}
\hline \multicolumn{1}{|c|}{ Ingredientes } & PB $\mathbf{( g , m l}$ ) & PL $\mathbf{~ g , ~} \mathbf{~ m l})$ & FC \\
\hline Camarão sem casca & 285,00 & 285,00 & 1,00 \\
\hline Cebola & 91,60 & 83,00 & 1,10 \\
\hline Alho & 5,00 & 4,00 & 1,25 \\
\hline Tomate & 215,53 & 130,00 & 1,66 \\
\hline Chuchu & 336,00 & 270,00 & 1,24 \\
\hline Cebolinha & 10,00 & 10,00 & 1,00 \\
\hline Sal & 3,00 & 3,00 & 1,00 \\
\hline Pimenta do reino & 1,00 & 1,00 & 1,00 \\
\hline Manteiga & 5,00 & 5,00 & 1,00 \\
\hline Corante (colorau) & 5,00 & 5,00 & 1,00 \\
\hline Extrato de tomate & 60,00 & 60,00 & 1,00 \\
\hline Água & & 200,00 & \\
\hline Folha de louro & 0,20 & 0,20 & 1,00 \\
\hline
\end{tabular}

Modo de preparo: Refogue os temperos (cebola e alho) na manteiga e acrescente os camarões. Em seguida adicione o chuchu cortado em cubos, o sal, a pimenta do reino, o extrato de tomate, as folhas de louro, o corante e a água. Cozinhe até que o chuchu esteja mole. Finalize com a cebolinha e os tomates em cubos.

INFORMAÇÃO NUTRICIONAL - Porção de: $150 \mathrm{~g}$

Valor energético: :80,36kcal

Proteínas: $10,38 \mathrm{~g}$

Carboidratos: $6,48 \mathrm{~g}$

Lipídios: $1,45 \mathrm{~g}$ 


\section{FICHA TÉCNICA DE PREPARO}

Tipo de Produto (Grupo): Pratos Principais

Item: Refogado de carne moída com palma

Rendimento: $1760 \mathrm{~g}$

Nível de complexidade: Baixo

Porção: $250 \mathrm{~g}$

\begin{tabular}{|l|c|c|c|}
\hline \multicolumn{1}{|c|}{ Ingredientes } & PB $(\mathbf{g}, \mathbf{m l})$ & PL $(\mathbf{g}, \mathbf{~ m l})$ & FC \\
\hline Acém moído & 500,00 & 500,00 & 1,00 \\
\hline Cebola & & 70,00 & \\
\hline Alho & & 10,00 & \\
\hline Tomate & & 80,00 & 1,20 \\
\hline Pimenta de cheiro & 12,00 & 10,00 & 2,00 \\
\hline Pimentão & & 40,00 & \\
\hline Palma & 600,00 & 300,00 & \\
\hline Coentro & & 10,00 & \\
\hline Cebolinha & & 10,00 & \\
\hline Sal & & 6,00 & \\
\hline Pimenta & & 5,00 & \\
\hline Óleo de soja & & 10,00 & \\
\hline Corante (colorau) & & 5,00 & \\
\hline
\end{tabular}

Modo de preparo: Corte a palma ao meio. Com a ajuda de uma faca amolada, retire o centro macio da palma, apoiando-a na tábua (essa parte externa é muito fibrosa!). Refogue os temperos (cebola, alho e pimentão) com o óleo de soja e acrescente a carne moída. Cozinhe por cerca de 15 minutos. Acrescente a palma cortada em cubos, cubra com água e cozinhe por mais 20 minutos. Finalize com o coentro a cebolinha e os tomates em cubos.

INFORMAÇÃO NUTRICIONAL - Porção de: $250 \mathrm{~g}$

Valor energético: $233,40 \mathrm{kcal}$

Proteínas: $25,52 \mathrm{~g}$

Carboidratos: $10,30 \mathrm{~g}$

Lipídios: 10,00g 


\section{FICHA TÉCNICA DE PREPARO}

Tipo de Produto (Grupo): Prato Principal

Item: Peixada alagoana

Rendimento: 662g

Porção: $100 \mathrm{~g}$

Nível de complexidade: Médio

\begin{tabular}{|l|c|c|c|}
\hline \multicolumn{1}{|c|}{ Ingredientes } & PB $\mathbf{( g , m l )}$ & PL $\mathbf{( g , ~} \mathbf{~ m} \mathbf{)}$ & FC \\
\hline Surubim (filé) & 210,00 & 210,00 & 1,00 \\
\hline Cebola & 95,00 & 88,00 & 1,08 \\
\hline Tomate & 100,00 & 56,00 & 1,79 \\
\hline Pimentão verde & 92,00 & 48,00 & 1,92 \\
\hline Cebolinha & 20,00 & 20,00 & 1,00 \\
\hline Alho com óleo & 5,00 & 5,00 & 1,00 \\
\hline Molho de tomate da casa & 166,00 & 166,00 & 1,00 \\
\hline Sal & 4,00 & 4,00 & 1,00 \\
\hline Azeite de oliva & 14,00 & 14,00 & 1,00 \\
\hline Chuchu cozido & 40,00 & 40,00 & 1,00 \\
\hline Cenoura cozida & 32,00 & 32,00 & 1,00 \\
\hline Leite de coco & 34,00 & 34,00 & 1,00 \\
\hline Ovo cozido & 62,00 & 62,00 & 1,00 \\
\hline
\end{tabular}

Modo de preparo: Descascar a cebola e cortar longitudinalmente em 8 partes. Tirar as sementes do tomate e cortar também em 8 partes. Limpar o pimentão e cortar em pedaços irregulares. Lavar a cebolinha e cortar em rodelas.

Ligar o fogo alto e aquecer uma frigideira $5 \mathrm{~cm}$ de altura. Colocar o azeite e o alho por 1 minuto. Colocar a cebola, o tomate e o pimentão. Mexer bem. Após 2 minutos, colocar o peixe e o sal. Após 2 minutos colocar o molho de tomate e tampar.

Com mais 3 minutos de cocção, colocar o chuchu cozido, a cenoura, a cebolinha e o leite de coco. Após 4 minutos colocar o ovo. Coccionar por mais 4 minutos e desligar. Temperatura 85으

INFORMAÇÃO NUTRICIONAL - Porção de: $100 \mathrm{~g}$

Valor energético: 93,25 Kcal

Proteínas: $55,74 \mathrm{~g}$

Carboidratos: $27,14 \mathrm{~g}$

Lipídios: $31,78 \mathrm{~g}$ 


\section{FICHA TÉCNICA DE PREPARO}

Tipo de Produto (Grupo): Pratos Principais

Item: Cozido maranhense

Rendimento: $2015 \mathrm{~g}$

Porção: $215 \mathrm{~g}$

Nível de complexidade: Médio

Porção (Medida Caseira): 2 colheres de sopa

\begin{tabular}{|l|c|c|c|}
\hline \multicolumn{1}{|c|}{ Ingredientes } & PB $\mathbf{( g , m l})$ & PL $\mathbf{~ g , ~} \mathbf{~ m l})$ & FC \\
\hline Acém & 410,00 & 378,00 & 1,08 \\
\hline Pimenta do reino & 2,00 & 2,00 & 1,00 \\
\hline Sal & 5,00 & 5,00 & 1,00 \\
\hline João gomes & 90,00 & 90,00 & 1,00 \\
\hline Vinagreira & 60,00 & 60,00 & 1,00 \\
\hline Maxixe & 272,50 & 218,00 & 1,25 \\
\hline Cebola & & 70,00 & \\
\hline Quiabo & 241,02 & 206,00 & 1,17 \\
\hline Abóbora & 453,00 & 300,00 & 1,51 \\
\hline Alho & & 10,00 & \\
\hline Tomate & & 110,00 & \\
\hline Pimentão & & 50,00 & \\
\hline Óleo de soja & 2,00 & 2,00 & 1,00 \\
\hline Louro & 2,00 & 2,00 & 1,00 \\
\hline Colorau & 6,00 & 6,00 & 1,00 \\
\hline Água & & 800,00 & \\
\hline
\end{tabular}

Modo de preparo: Refogue todos os temperos com o óleo de soja, acrescente a carne em cubos, a água e cozinhe. Quando estiver quase pronto, acrescente os legumes partindo do mais duro. Acrescente o joão gomes e a vinagreira já escaldados.

INFORMAÇÃO NUTRICIONAL - Porção de: $215 \mathrm{~g}$

Valor energético: $135,68 \mathrm{kcal}$

Proteínas: $13,16 \mathrm{~g}$

Carboidratos: $14,17 \mathrm{~g}$

Lipídios: 2,92g 


\section{FICHA TÉCNICA DE PREPARO}

Tipo de Produto (Grupo): Pratos Principais

Item: Rubacão

Rendimento: $1090 \mathrm{~g}$

Porção: $90 \mathrm{~g}$

Nível de complexidade: Médio

Porção (Medida Caseira): 3 colheres de sopa

\begin{tabular}{|l|c|c|c|}
\hline \multicolumn{1}{|c|}{ Ingredientes } & PB $\mathbf{( g , m l})$ & PL $\mathbf{~ g , ~} \mathbf{~ m l})$ & FC \\
\hline Charque & 190,00 & 145,00 & 1,31 \\
\hline Feijão branco & 100,00 & 100,00 & 1,00 \\
\hline Bacon & 10,00 & 10,00 & 1,00 \\
\hline Lombo de porco & 365,00 & 300,00 & 1,22 \\
\hline Alho & & 15,00 & \\
\hline Cebola & & 100,00 & \\
\hline Pimentão & & 50,00 & 1,00 \\
\hline Coentro & 5,00 & 5,00 & 1,00 \\
\hline Cebolinha & 5,00 & 5,00 & 1,10 \\
\hline Pimenta de cheiro & 5,50 & 5,00 & 1,00 \\
\hline Arroz & 50,00 & 50,00 & 1,00 \\
\hline Sal & 5,00 & 5,00 & \\
\hline Água & & 400,00 & \\
\hline
\end{tabular}

Modo de preparo: Refogue o bacon, acrescente o charque e os temperos. Acrescente o feijão e metade da água e cozinhe. Acrescente o arroz e cozinhe até que os grão estejam prontos. Finalize com o coentro e a cebolinha picados.

INFORMAÇÃO NUTRICIONAL - Porção de: 90g

Valor energético: 288,28kcal

Proteínas: $25,13 \mathrm{~g}$

Carboidratos: $21,69 \mathrm{~g}$

Lipídios: $11,23 \mathrm{~g}$ 


\section{FICHA TÉCNICA DE PREPARO}

Tipo de Produto (Grupo): Guarnição

Item: Refogado de maxixe

Rendimento: $365 \mathrm{~g}$

Nível de complexidade: Baixo

Porção: $36 \mathrm{~g}$

\begin{tabular}{|l|c|c|c|}
\hline \multicolumn{1}{|c|}{ Ingredientes } & PB $\mathbf{( g , m l})$ & PL $\mathbf{( g , ~} \mathbf{~ m l})$ & FC \\
\hline Maxixe & 200,00 & 185,00 & 1,08 \\
\hline Cebola & & 53,00 & \\
\hline Alho & & 5,00 & \\
\hline Pimentão verde & & 29,00 & \\
\hline Extrato de tomate & 20,00 & 20,00 & 1,00 \\
\hline Manteiga & 5,00 & 5,00 & 1,00 \\
\hline Sal & 3,00 & 3,00 & 1,00 \\
\hline Pimenta do reino & 1,00 & 1,00 & 1,00 \\
\hline Água & & 100,00 & \\
\hline
\end{tabular}

Modo de preparo: Refogue os temperos (cebola, alho e pimentão) na manteiga, acrescente os maxixes cortados em rodelas, o extrato de tomate, o sal, a pimenta do reino ea água. Cozinhe até que o maxixe esteja macio.

INFORMAÇÃO NUTRICIONAL - Porção de: $36 \mathrm{~g}$

Valor energético: $31,90 \mathrm{kcal}$

Proteínas: $1,22 \mathrm{~g}$

Carboidratos: $4,07 \mathrm{~g}$

Lipídios: $1,20 \mathrm{~g}$ 


\section{FICHA TÉCNICA DE PREPARO}

\section{Tipo de Produto (Grupo): Guarnição}

\section{Item: Vatapá de inhame}

Rendimento: $450 \mathrm{~g}$

Porção: $54 \mathrm{~g}$

Nível de complexidade: Médio

Porção (Medida Caseira): 3 colheres de sopa

\begin{tabular}{|c|c|c|c|}
\hline Ingredientes & PB (g,ml) & PL $(\mathrm{g}, \mathrm{ml})$ & FC \\
\hline Cebola & 75,00 & 65,00 & 1,15 \\
\hline Inhame & 335,00 & 290,00 & 1,16 \\
\hline Castanha de caju & 5,00 & 5,00 & 1,00 \\
\hline Amendoim & 7,00 & 7,00 & 1,00 \\
\hline Gengibre & 6,00 & 4,00 & 1,50 \\
\hline Camarão seco & 150,00 & 150,00 & 1,00 \\
\hline Sal & 5,00 & 5,00 & 1,00 \\
\hline Azeite de dendê & 5,00 & 5,00 & 1,00 \\
\hline Pimena de cheiro & 5,00 & 4,00 & 1,25 \\
\hline Alho & 4,3 & 4,00 & 1,08 \\
\hline
\end{tabular}

Modo de preparo: Refogue a cebola, o alho e a pimenta de cheiro no azeite de dendê. Acrescente o camarão seco dessalgado em água gelada por cerca de 30 minutos, trocando a água. Cozinhe o inhame em água, reservando quando pronto. Leve o refogado ao liquidificador com o inhame, o amendoin, a castanha e $o$ gengibre. Acrescente um pouco da água do cozimento do inhame se necessário.

Retorne o creme para a panela, aqueça e sirva em seguida.

INFORMAÇÃO NUTRICIONAL - Porção de: $54 \mathrm{~g}$

Valor energético: $101,77 \mathrm{kcal}$

Proteínas: $6,78 \mathrm{~g}$

Carboidratos: $14,62 \mathrm{~g}$

Lipídios: $1,79 \mathrm{~g}$ 


\section{FICHA TÉCNICA DE PREPARO}

Tipo de Produto (Grupo): Guarnição

Item: Farofa de banana da terra com cenoura

Rendimento: $1245 \mathrm{~g}$

Porção: $80 \mathrm{~g}$

Nível de complexidade: Baixo

Porção (Medida Caseira): 2 colheres de sopa

\begin{tabular}{|l|c|c|c|}
\hline \multicolumn{1}{|c|}{ Ingredientes } & PB $\mathbf{( g , m l})$ & PL $\mathbf{( g , ~} \mathbf{~ m l})$ & FC \\
\hline Banana da terra & 535,00 & 335,00 & 1,60 \\
\hline Cebola & 154,00 & 144,00 & 1,07 \\
\hline Alho & & 15,00 & \\
\hline Corante (colorau) & & 2,00 & 1,11 \\
\hline Cenoura ralada & 155,00 & 140,00 & \\
\hline Óleo de soja & 10,00 & 10,00 & \\
\hline Manteiga & 40,00 & 40,00 & \\
\hline Farinha de mandioca & 250,00 & 250,00 & \\
\hline Cebolinha & 20,00 & 20,00 & \\
\hline Sal & 3 & 3,00 & \\
\hline
\end{tabular}

Modo de preparo: Refogue os temperos (cebola e alho) na manteiga com o óleo acrescente a cenoura ralada, o colorau, as bananas cortadas em cubos e continue refogando. Baixe o fogo e acrescente a farinha de mandioca. Permaneça no fogo por aproximadamente mais 10 minutos, mexendo sempre. Acrescente $o$ sal e finalize com a cebolinha.

INFORMAÇÃO NUTRICIONAL - Porção de: $80 \mathrm{~g}$

Valor energético: 149,82kcal

Proteínas: $1,10 \mathrm{~g}$

Carboidratos: $28,24 \mathrm{~g}$

Lipídios: $3,59 \mathrm{~g}$ 


\section{FICHA TÉCNICA DE PREPARO}

Tipo de Produto (Grupo): Guarnição

Item: Refogado de mamão verde

Rendimento: $575 \mathrm{~g}$

Nível de complexidade: Baixo

Porção: $85 \mathrm{~g}$

\begin{tabular}{|l|c|c|c|}
\hline \multicolumn{1}{|c|}{ Ingredientes } & PB $(\mathbf{g}, \mathbf{m l})$ & PL $\mathbf{( g , ~} \mathbf{~ m l})$ & FC \\
\hline Mamão verde & 559,00 & 363,00 & 1,54 \\
\hline Cebola & & 79,00 & 1,19 \\
\hline Alho & 19,00 & 16,00 & \\
\hline Tomate & & 104,00 & 1,00 \\
\hline Pimentão & & 65,00 & 1,00 \\
\hline Coentro & 5,00 & 5,00 & 1,00 \\
\hline Cebolinha & 5,00 & 5,00 & 1,00 \\
\hline Sal & 3,00 & 3,00 & \\
\hline Óleo de soja & 1,00 & 1,00 & \\
\hline Água & \multicolumn{3}{|c}{} \\
\hline
\end{tabular}

Modo de preparo: Descasque o mamão e corte em cubos (ou lascas). Refogue os temperos (cebola, alho e pimentão) com o óleo de soja, acrescente o mamão cortado e a água. Tempere com o sal e cozinhe até que esteja mole. Finalize com o coentro e a cebolinha.

INFORMAÇÃO NUTRICIONAL - Porção de: $85 \mathrm{~g}$

Valor energético: $37,37 \mathrm{kcal}$

Proteínas: 0,96g

Carboidratos: $7,81 \mathrm{~g}$

Lipídios: $0,25 \mathrm{~g}$ 


\section{FICHA TÉCNICA DE PREPARO}

\section{Tipo de Produto (Grupo): Guarnição}

Item: Frigideira de maturi

Rendimento: $1950 \mathrm{~g}$

Porção: $115 \mathrm{~g}$

Nível de complexidade: Médio Porção (Medida Caseira): 2 colheres de sopa

\begin{tabular}{|l|c|c|c|}
\hline \multicolumn{1}{|c|}{ Ingredientes } & PB $\mathbf{( g , m l )}$ & PL $\mathbf{( g , ~} \mathbf{~ m})$ & FC \\
\hline Maturi & 400,00 & 400,00 & 1,00 \\
\hline Pimenta de cheiro & 22,00 & 17,00 & 1,29 \\
\hline Cebola & & 100,00 & \\
\hline Tomate & & 138,00 & 1,00 \\
\hline Coentro & 10,00 & 10,00 & 1,00 \\
\hline Cebolinha & 10,00 & 10,00 & 1,38 \\
\hline Ovo (claras) & 110,00 & 80,00 & 1,00 \\
\hline Ovo (inteiro) & 110,00 & 110,00 & \\
\hline Cenoura & & 120,00 & \\
\hline Batata inglesa & & 190,00 & \\
\hline Alho & & 10,00 & \\
\hline Pimentão verde & & 80,00 & \\
\hline Vagem & & 200,00 & \\
\hline Sal & & 10,00 & \\
\hline Óleo de soja & 10,00 & \\
\hline Pimenta & & 10,00 & \\
\hline
\end{tabular}

Modo de preparo: Cozinhe cada um dos legumes saparadamente e reserve. Refogue todos os temperos (cebola, alho, pimenta de cheiro e pimentão) e acrescente o maturi. Tempere com sal e pimenta, cubra com água (ou com algum caldo natural, como carne ou frango) e deixe cozinhar até que o maturi mude cor, ficando branco. Acrescente os legumes cozidos, o coentro a cebolinha e os tomates em cubos e deixe esfriar. Bata as 4 claras em ponto de neve e acrescente as duas gemas no final. Separe metade das claras em neve e misture com o refogado já frio. Despeje nu m refratário untado com manteiga e adicione o restante das claras. Leve ao forno pré-aquecido por cerca de 20 minutos.

INFORMAÇÃO NUTRICIONAL - Porção de: $115 \mathrm{~g}$

Valor energético: $245,38 \mathrm{kcal}$

Proteínas: $8,55 \mathrm{~g}$

Carboidratos: $15,72 \mathrm{~g}$

Lipídios: 16,49g 


\section{FICHA TÉCNICA DE PREPARO}

\section{Tipo de Produto (Grupo): Guarnição}

Item: Paçoca de carne seca com banana da terra

Rendimento: $520 \mathrm{~g}$

Nível de complexidade: Baixo

Porção: $36 \mathrm{~g}$

\begin{tabular}{|l|c|c|c|}
\hline \multicolumn{1}{|c|}{ Ingredientes } & PB $\mathbf{( g , m l})$ & PL $\mathbf{( g , ~} \mathbf{~ m l})$ & FC \\
\hline Charque & 200,00 & 170,00 & 1,18 \\
\hline Cebola & & 60,00 & \\
\hline Farinha de mandioca & 150,00 & 150,00 & 1,00 \\
\hline Óleo de soja & 20,00 & 20,00 & 1,00 \\
\hline Banana da terra & 230,00 & 170,00 & 1,35 \\
\hline
\end{tabular}

Modo de preparo: Retire o excesso de gordura da carne e asse-a em forno pré-aquecido. Refogue a cebola no óleo de soja, acrescentando a carne e a farinha de mandioca. Leve tudo ao liquidificado ou a um pilão

INFORMAÇÃO NUTRICIONAL - Porção de: $36 \mathrm{~g}$

Valor energético: $147,57 \mathrm{kcal}$

Proteínas: $4,59 \mathrm{~g}$

Carboidratos: $20,59 \mathrm{~g}$

Lipídios: 5,22g 